\title{
Antecedentes históricos y tradicionales del origen y carta de fundación, derecho, usos y costumbres del Principado de Andorra.
}

Existe un hermoso rincón, prolongación de las tierras catalanas, incrustado en los Pirineos catalanes, que unos llaman indebidamente república de Aṇdorra y otros Principado, como genuinamente corresponde por derechio y tradición histórica. Por su especial régimen de autonomía, y sus patriarcales costumbres, es digno de conocerse y de ser divulgado, y también es digno de objetivo de estudios de su especial vida local. Este es el motivo que nos impulsa a describir, en amplio plano, lo más saliente de estos valles, sin perjuicio de volver más adelante sobre los aspectos netamente municipales.

Por los años 1933 y 1934, y como consecuencia de nuestros viajes por los Valles de Andorra, publicamos varios artículos con ilustraciones fotográficas, relativos a aquellos Valles, y después de hacer una breve reseña de sus antecedentes históricos $y$ tradicionales, $y$ con datos $y$ argumentos fehacientes, demostrábamos la improcedencia, en el aspecto histórico, político y jurídico de ser denominado aquel régimen autónomo, del Valle de Andorra, con el apelativo de república, puesto que el que con propiedad debe ostentar, con todos los caracteres de legitimidad, propiedad y derecho, es el de "Principado de Andorra".

$\mathrm{Y}$ alegábamos entre otras razones, la suprema y principal de corresponder a un Príncipe de la Iglesia, el Obispo de Urgel, el ejercicio del dominio y soberanía espiritual, jurídica y territorial, desde sus orígenes en la época de la Reconquista hasta nuestros días.

En nuestros recorridos por los hermosos Valles andorranos, siempre verdes, constantemente irrigados, acogedores siempre, ascendíamos unas veces por las encumbradas laderas cuajadas de frondosas hierbas en sus típicas praderas naturales, y otras por las faldas de sus montañas, tupidas por frondosos bosques de robles, castaños, hayas, abetos, fres- 
nos, encinas, avellanos, sauces, pinos, sabinas, etc., etc., y luego descendiendo lentamente para recogernos en alguno de los caseríos de sus seis Parroquias, íbamos desgranando muchas veces las patróticas y religiosas endechas de aquel vate, tan sencillo y místico a la vez, Mosén Jacinto Verdaguer, autor de la Atlántida, que le fué solicitada personalmente por el Papa León XIII en la visita que le hizo el ilustre poeta y sacerdote catalán, Mosén Cinto.

Otras veces, meditábamos sobre los profundos pensamientos del Criterio y la Filosofía de Balmes, de cuyos dos autores hemos contemplado autógrafos que se conservan en el Museo Arqueológico Diocesano de Vich.

$\mathrm{Y}$ otras veces leíamos trozos del pensamiento profundo de Raimundo Lulio, a cưyo padre, caballero catalán, la alta empresa del Rey Don Jaime I, llevó a la conquista de Mallorca, felizmente realizada en 31 de diciembre, fiesta de San Silvestre y Santa Coloma, del año 1229.

$\mathrm{Y}$ alternativamente considerábamos también la figura señera de San Raimundo de Peñafort, nacido en el castillo de su nombre, cerca de la ciudad de Villafranca del Panadés, que como Verdaguer, recorrió tambien los Valles de Andorra, sirviendo de poderoso auxiliar al Obispo de Urgel. Este gran santo, Compiladior de las Decretales, Penitenciario Papal, del cual se dijo: "Este santo varón, vuelve de la Curia romana, tal cual entró en ella. Su encumbramiento no ha podido alterar en nada su humildad, nos cautivó por su gran ciencia y santidad».

Estas figuras catalanas parece que nos ayudaban a comprender mejor las observaciones de "visu" que íbamos recogiendo por tierras catalanas y por los Valles de Andorra.

Pues bien, después de haber recorrido las seis Parroquias andorranas, y admirado sus vetustas y milenarias iglesias, casi todas ellas de antiguo estilo románico, y la profusión de ermitas y cruces, íbamos profundizando en las consideraciones que esta trabazón religiosa nos sugería, apreciando en su verdadero valor, cómo la fe, que según San Bernardo, se ha de inculcar y persuadir, pero nunca imponer, ha venido manteniéndose vigorosa entre los andorranos, sin que hayamos podido observar en los naturales del país vestigios de supersticiones ni errores, a través de las diversas vicisitudes por que ha atravesado nuuestra patria, $y$ a pesar de las corrientes evolutivas del pensamiento, de los enciclopedistas, que tanto juego dieron con la reforma y revolución francesa.

Todo ello nos hacía exclamar llenos de emoción y con sentido auténticamente cristiano, y con significación de verdadera y transcendente 
fe católica, aquellas frases que en obsequio de la Roma pagana, pronunciara Tito Livio: "No hay un solo rincón de estos Valles que no se halle impregnado de sentido religioso, y que no sea ocupado por una advocación divina o celestial».

Pudimos en nuestros recorridos admirar una hermosa, riquísima y abundante biblioteca, con su sala-museo contigua, de Historia Natural, en cuyas colecciones había ejemplares de América y de la India.

Llegamos por fin a la iglesia de Llorts, aldea que corresponde a la Parroquia de Ordino, y cual no sería nuestra sorpresa, cuando se ofrecía a nuestros ojos un altar dedicado a Nuestra Señora del Pilar, que data, según referencias, del siglo xIX.

De todas estas visitas e impresiones, tomamos las correspondientes notas y fotografías, adquirimos algunos libros, pero todo lo perdimos, al igual que nuestros bienes-muebles y patrimonio domiciliario, en la pasada contienda civil.

Guardamos, empero, vivos y bien grabados los recuerdos y las impresiones $\mathrm{y}$. con ellos, $\mathrm{y}$ con los testimonios fidedignos de tradiciones $\mathrm{y}$ escritos y libros oonsultados, y los nuevamente adquiridos, nos proponemos dar una referencia para ofrecer al mundo católico una prueba fehaciente y auténtica de la extensión del culto y devoción a Nuestra Señora del Pilar, que se le tributa en el Principado de Andorra.

Pero conviene enmarcarla debidamenite, dando al efecto algunos detalles interesantísimos relacionados con este hermoso rincón de España. para desvanecer el error de muchos que consideran como parte integrante de Francia. No nos causó extrañeza ver arraigada en un rincón del suelo hispánico la devoción a Nuestra Señora del Pilar, ya que en este Principado de Andorra ejerce todos los derechos de dominio y soberanía espiritual territorial y jurídica, con catgoría de señorío, el Obispo. de Urgel, $y$ por ende ha tenido buen cuidado la mitra de Urgel, con un celo y vigilancia constantes, de mantener viva la devoción ferviente a la Santísima Virgen María. Y así vemos entre las advocaciones principales, las que celebran los andorranos a Nuestra Señora de Meritxell, Patrona del Principado de Andorra; a Nuestra Señora de Conólic que se venera en S. Julián de Loria, y a la Santísima Virgen del Pilar, que se venera eñ Llorts, de la Parroquia de Ordino. 


\section{I.-DESCRIPCION DE LOS VALLES DE ANDORRA}

En la vertiente meridional española de los Pirineos catalanes existe una zona perimetral de hondos valles y de altas montañas, unos y otros a altura variable entre los 650 a los 3.141 metros sobre el nivel del mar, que constituyen el genuinamente denominado "Principado de Andorra", con régimen autónomo y que en forma de polígono, tiene su lado norte formando la misma cresta de la cordillera Pirenaica, sirviendo de límite con Francia y los restantes lindan con tierras catalanas y en forma estrecha se entra por los confines de Urgel, con cuya capital o cíudad, plaza fuerte, Seo de Urgel, se comunica por carretera costeada e iniciada por el Obispo de Urgel su Príncipe y Señor.

Recientemente han sido fijadas por Gaulier y Marcelo Chevalier los signos geodésicos de las fronteras, en la forma que pueden ver los estudiosos en la Enciclopedia Espasa, en la Voz Andorra, en el Apéndice a la misma.

La extensión superficial de Andorra se calcula en 495 kilómetros cuadrados, y su población oscila entre los 7.000 a los 8.500 habitantes, que suele verse aumentada en los meses estivales, en que afluyen a este país de Francia y de España, en plan turístico, o para buscar un reposo y un descanso en estos tranquilos y apacibles valles.

Los ríos más importantes son el Ariège, afluente del Garona (francés) y los dos ríos Valira el del Norte y el del Este que son alimentados por multitud de arroyuelos que trazan dos valles profundos, y se reunen en la capital del Principado Andorra la Vella (Andorra la Vieja), para formar el gran río Valira que va trazando la (y)" griega, desde sus comienzos al final.

Entre las rocas arcaicas o de origen interno, la pigmatita es la que más abunda. El granito ofrece, en general, como caracteres macroscópicos, el feldespato blanco y en algunas partes rosáceo; el cuarzo gris blanquecino, y la mica gris, negruzca o negra, etc.

Del período primario hállanse representados los terrenos cámbrico. silúrico y tal vez el devónico. En la composición de estos terrenos entran prịicipalmente, al parecer, gneis, micazitas, talquitas, filadios, pizarras, grawakas, cuarcitas y calizas, cuyas capas, aun cuando sufran muy poca variedad e indeterminación en sus líneas estratográficas, con todo, su dirección más general puede reducirse a la de Levante o Poniente y su buzamiento (inclinación), al Norte.

Las aguas minerales abundan en estos valles. Son muy famosas las 
ferruginosas, de las que en Llorts existen dos manantiales. En Apal hay. uno y en el Puy el conocido por Font Roja, y el más caudaloso en el valle de Prat Primer.

También otras aguas minerales abundan. Pero las más notables son las sulforosas y nitrogenadas-sulforosas de Las Escaldas, que emergen a la temperatura de los 60 a los 85 grados C. Estas aguas termales son de primerísima calidad. Existen varios balnearios de estas aguas para el tratamiento de las enfermedades del artritismo en sus diversas manifestaciones.

En las montañas se dan canteras de piedras minerales, entre los que se encuentran preciosos jaspes y mármoles, piedra y cal.

Los filiados tegulares abundan sobre todo en Mertixel y los Bons, que proporcionan delgadas y finas lajas de hermoso color negro muy a propósito para cubiertas de edificios al estilo francés, y que abundan por el Valle de Arán con más profusión que en estos valles.

Existen también ricos yacimientos de hierro, que en otro tiempo fueron objeto de explotación por el procedimiento de las antiguas forjas catalanas.

También se aprecian por los técnicos, minerales de cobre, de plomo y de óxido de hierro.

La flora es abundante y preciosa, y las hierbas aromáticas y medicinales son variadísimas. En estas alturas se dan mariposas especiales que los aficionados coleccionan para enriquecer sus gabinetes de Historia Natural.

En las partes bajas abundan los árboles frutales, en invierno los perales, manzanos, nogales, castaños y otros.

Entre la fauna puede contarse actualmente algún jabalí y lobo en invierno, y en abundancia las zorras, martas, cabras montesas, gato montés, gamuzas, liebres y conejos.

De entre las aves, existen en los escarpados, el águila, gavilán y otras de rapiña.

En las cimas altas existen perdices blancas, y en las tierras dedicadas al cultivo y sus contornos se dan las perdices comunes, y en las partes bajas y en las temporadas de las emigraciones, existen becadas, becacines, patos salvajes en busca de los lagos, etc.

La perdiz corriente se halla en tanta abundancia que siempre que hemos ido a aquellos valles las hemos comido, y además la tradición enseña que una de las sesiones del Consejo General se le llamaba antiguamente la sesión de la Perdiz, porque era costumbre servir una perdiz 
a cac̉a uno de los Consejeros y su Secretario y a cacia uno de los invitados.

En verano los campos y prados se inundan de codornices. $Y$ se cazan por los valles donde no hay caseríos cerca, muy cómodamente, pues no están fogueadas como por otras partes de España donde se las persigue de continuo.

En tiempos, también, abundaban los osos. Actualmente en los inviernos más crudos suelen transitar algunos. Antiguamente debieron abundar porque los andorranos celebraban la "Festa de la Osa" (Fiesta del Oso), consistente en una farsa imaginiada por los pastores montañeses, cuya acción representa todas las peripecias de la lucha enconada para dar muerte a un oso que hace su aparición en un prado en el momento que los guadañadores se disponen a merendar. Es muy emocionante. $\mathrm{Y}$ a este respecto recuerdo haberme referido algún caso peligroso de encuentros de cazadores y pastores con osos, y con el fin de los que nos leyeren puedan sacar su lección y aprovecharla referiremos el caso que en la vida de Santa Isabel de Portugal, se refiere de su mismo esposo Dionisio, Rey de Portugal, que yendo éste de caza hirió levemente a un oso, que huyó y se guareció en un lugar escabroso y seguro, instintwamente elegido por la fiera. El Rey, solo, a caballo, la persiguió $\mathrm{Y}$ cuando hubo llegado a aquel lugar, salió el oso de repente y no pudiendo el Rey avanzar ni retroceder, fué derribado de un zarpazo por la fiera, y cayó al suelo. En tan apurado trance se acordó de que su esposa tenía gran devación a San Luis, Obispo de Tolosa, y exclamó: "Señor Jesucristo, libradme de este trance por los méritos de San Luis a quien la Reina, mi mujer, tiene, $\tan$ ferviente y entera devoción". Instantáneamente vió junto a él un fraile menor, con mitra de Obispo, que con sereño rostro y sonriéndole le dijo. "¿Qué haces...? No temas... Echa mano del puñal que llevas en la cintura y mata al oson.

El Rey recobró la serenidad y el ánimo, que el pavor le había hecho perder y sacó el arma y con la mano derecha que tenía libre, pues a todo esto el oso le había echado la zarpa en el pecho, la clavó con brío en el costado del oso que dejó de oprimirle el pecho y pudo el Rey levantarse y acabarlo de matar.

Sirva de ejemplo el hecho y que los andorranos cazadores y pastores se encomienden a San Luis, Obispo de Tolosa.

En los estanques $y$ ríos se pescan en abundancia sabrosas truchas, 
muy estimadas por los visitantes de los valles, algunas anguilas y otros peces.

Como la extensión de tierras cultivables es muy reducida, los andorranos han sido impelidos por la misma naturaleza a dejar indivisas vastas superficies. $\mathrm{Y}$ en general las praderas naturales suelen ser utilizadas por las clases acomodadas que disponen de capital para comprar ganado y recriarlo en estas praderas.

En cambio la clase pobre utiliza los bosques para la producción de leña y de madera de construcción, con determinadas condiciones impuestas por el Consejo General de los Valles. Pues el aprovechamiento colectiva de las praderas, de las leñas y de los bosques se halla cuidadosamente reglamentado.

Son célebres las bohigues, que en Castilla llamamos dehesas boyales, que consisten en tierras comunales que son cedidas a los particulares por los Comunes o Parroquias, con destino al cultivo, pero en calidad de mero usufructuario.

Las hierbas en los prados, sabrosas y alimenticias para los ganados, y el tabaco en las tierras son los dos productos de mayor rendimiento en los valles.

Cultívanse también, en las tierras bajas, la patata, el trigo, el centeno, maíz, cebada, guisante, habas, habichuelas y otras legumbres.

La ganadería es de una riqueza importantísima y abarca a todas las clases: cabrío, lanar, vacuno, caballar, mular y asnal. De éstas, compran en Francia para su recrío y las llevan a las ferias de la provincia de Lérida, Gerona y Huesca principalmente. Las vacas lecheras en los últimos años han aumentado singularmente, transportando a Seo de Urgel, donde existen importantes fábricas de mantequilla y queso y derivados, la leche, o también el queso ya elaborado a los mercados y tiendas de Seo de Urgel.

En el verano tienen la costumbre, sobre todo los pastores y ganaderos propios, de establecerse con sus ganados en las partes altas de las montañas, que al licuarse las nieves reverdecen con sabrosos y verdes pastos. Forman granjas en las cuales establecen con separación dos secciones: a un lado agrupan y resguardan sus ganados protegidos de diversas formas con sus vigilantes y mastines, y a otro lado forman sus alojamientos las personas, sobre las pieles o la paja, y abrigados con sus respectivas mantas, de las que el montañés andorrano va siempre provisto, lo mismo que de su buen garrote y cuchillo, y no sabemos si también algún arma de fuego, ya que no es extraño ver varias 
escopetas en cada granja. A estos agrupamientos se les llama cortals, y son muy famosos por su importancia y amplitud los de San Jaime dels Cortatals, de Excamp, de San Miguel de Engolasters y de Canólic. No existen iglesias por estas alturas, pero no falta su santuario o ermita donde se celebran las misas en determinados días festivos de estas épocas estivales. Esta es la plácida vida pastoril de la que tan poéticamente nos dejó episodios escritos el inmortal Cervantes, fracmentariamente en el Quijote y en forma más amplia en La Galatea, 'y en Persibes y Segismunda, cuyos libros no debieran faltar, en cada cortals, para solaz de estas gentes.

$Y$ ya que tocamos estas costumbres tan raciales y patriarcales, recordando algunas églogas de Mosén Jacinto Verdaguer y algunos párrafos en prosa de grandes escritores, finalizamos esta descripción de los valles, que territorialmente se dividen en seis parroquias o comunes o municipios, con aldeas y caseríos agregados, este canto a los valles de Andorra, alusivo en principio a los Cortals, y finalizando con una impresión general de los valles o Parroquias y sus contornos.

La misma estructura del país es la que impone a los habitantes esta emigración estacional a las alturas, la que, por otra parte, realizan gustosos y alegres, dejando el fondo y la estrechura del Valle para permanecer algunos días en el Cortal, donde hacen una vida idílica, llena de poesía, contemplando el hermoso panorama que les ofrecen las cumbres de sus más altas montañas coronadas de nieve, dedicándose al deporte de la caza, y fatigados, apagando su sed en las limpias y puras ondas de frescas y cristalinas fuentes; allí recostados, cual otro Titiro de las Eglogas virgilianas, se recrean a la sombra bienhechora de viejos y corpulentos pinos, respirando a sus anchas un aire puro y sutil, saturado de los balsámicos efluvios de mil hierbas aromáticas, que brotan en las rocas; alli se adormecen al dulce susurro del blando céfiro, jugueteando con las florecillas de los más vivos y variados colores, que esmaltan la alfombra de verde césped, y al murmullo de mansos arroyuelos, que serpentean entre las breñas; allí, su vista, limitada por cortos horizontes en los valles donde moran en invierno, se explaya perdiéndose en la lotananza de un horizonte dilatado bajo un cielo azul y riente, puro y serenlo, esplendente de luz y color.

Allí, finalmente, experimentan al atardecer emociones nunca sentidas, como las que producen el continuo tintineo de las esquilas de rebaños invisibles y el lejano sonido de una campana anunciadora del confortante toque del Angelus, más perceptible, si cabe, en aquella tan 
callada hora de calma, de paz y de tranquilidad $y$, sobre todo, la indescriptible belleza de aquellas noches sin par, en las que las estrellas cuajan el inmenso tul del cielo de riquísima pedrería y toman allí brillo de una intensidad sin igual, poetizado más y más por los plateados rayos de la luna, convirtiendo aquella bendita soledad en un paisaje sublime, como de ensueño y de encantos naturales; de tal suerte que el espíritu, sobrecogido y absorto en estas contemplaciones, olvidándose de todo lo terreno, sólo tiene ojos para mirar al cielo y contemplar el augusto trono de Dios, a quien con reverencia y con profunda admiración, adora ante la magnificiencia de sus obras, y no puede menos de sentirse movido a exclamar con el Príncipe de nuestros líricos españoles: "iQué descansada vida la del que huye del mundanal ruido...!"

Porque esta traniquilidad paradisíaca implica un silencio sepulcral, sólo interrumpido por el alegre canto de las aves y el rumor de las intranquilas aguas del río y de las pequeñas cascadas en que, juguetona, se cesliza por sus laderas, elevando a Dios, noche y día, su eterna canción de alabanza.

(Continuará.)

Luis Negro Laínéz 